\title{
Essential Training Knowledge for Physicians Working in the Field of Professional Training and Development, and Medical Schools' Instruction
}

\author{
Aamir Jalal Al-Mosawi* \\ Head, Iraq Headquarter of Copernicus Scientists International Panel, Baghdad, Iraq
}

*Corresponding author: Aamir Jalal Al-Mosawi, Head, Iraq Headquarter of Copernicus Scientists International Panel, Baghdad, Iraq

\begin{abstract}
Background: The increasing complexity of medical care environment, and medical education and practices made understanding the principles and concepts of training, development, and the related concepts and disciplines necessary for doctors practicing at almost any level in a healthcare system. The aim of this paper is to identify the essential training knowledge needed by physicians working in the field of professional training and development (Professional trainers) and medical schools' instruction. These essential knowledges should include in the content of any training of the trainer (TOT) courses conducted for physicians.
\end{abstract}

Materials and methods: More than 100 relevant publications were identified and reviewed.

Results: The essential training knowledge needed by physicians working in the field of professional training and development (Professional trainers) included adequate knowledge about accreditation of a training course, the need for professional training, training and development in a healthcare organization, domains of change during training, the influences of professional training and development, the training process (Stages of the training process, training needs, training needs analysis methods, training needs analysis methods, Setting SMART training objectives), designing an effective training course, Popular training methods, What a professional trainer needs to understand and do before and during a training course development, ,how to conduct a professional training course, the main principles of training course evaluation, the evaluation of a training course using Kirkpatrick's four levels of evaluation, the commonly used methods of instruction and training, training and instruction effectiveness, training and instruction effectiveness evaluation, participants learning assessment during training and instruction, learning process for trainers and instructors, VAK learning model, VARK learning model of Neil D. Fleming, the 4MAT learning model of Bernice McCarthy, the application of learning theories in training and instruction, the cognitive (knowledge-based) domain of learning and training , Bloom's taxonomy and its practical value in training and medical schools' instruction, behaviorist model of learning (The operant conditioning), the ideas of John Dewey relevant to training and instruction, constructivist learning theory, Jean Piaget's cognitive theory, the practical applications of Jean Piaget ideas in training and instruction, Lev Vygotsky ideas' practical application in training and instruction including the zone of proximal development, the concept of Instructional scaffolding suggested by Jerome Seymour Brunerm, the fundamental principles of learning relevant to training and medical schools' instruction, the fundamental principles of learning relevant to training and medical schools' instruction, the principles of Adult learning (Andragogy) suggested by Malcolm Shepherd Knowles, the principles of the constructivist's approaches for adult training and instruction, the main principles of adult training and instruction that distinguish adult learners from children and youth, the principles of making presentation, what a TOT course is all about and he need for TOT courses.

Conclusion: This research article provided a compendium of the essential training knowledge needed by physicians working in the field of professional training and development (Professional trainers).

Keywords: Professional training; physician development; medical schools' instruction; TOT courses

\section{Introduction}

The increasing complexity of medical care environment, and medical education and practices made understanding the principles and concepts of training, development, and the related concepts and

disciplines necessary for doctors practicing at almost any level in a healthcare system. The aim of this paper is to identify the essential training knowledge needed by physicians working in the field of 
professional training and development (Professional trainers) and medical schools' instruction. These essential knowledges should include in the content of any training of the trainer (TOT) courses conducted for physicians.

\section{Materials and Methods}

More than 100 relevant publications were identified and reviewed.

\section{Results}

The essential training knowledge needed by physicians working in the field of professional training and development (Professional trainers) included adequate knowledge about accreditation of a training course, the need for professional training, training and development in a healthcare organization, domains of change during training, the influences of professional training and development, the training process (Stages of the training process, training needs, training needs analysis methods, training needs analysis methods, Setting SMART training objectives), designing an effective training course, Popular training methods, What a professional trainer needs to understand and do before and during a training course development, ,how to conduct a professional training course, the main principles of training course evaluation, the evaluation of a training course using Kirkpatrick's four levels of evaluation, the commonly used methods of instruction and training, training and instruction effectiveness, training and instruction effectiveness evaluation, participants learning assessment during training and instruction, learning process for trainers and instructors, VAK learning model, VARK learning model of Neil D. Fleming, the 4MAT learning model of Bernice McCarthy, the application of learning theories in training and instruction, the cognitive (knowledgebased) domain of learning and training, Bloom's taxonomy and its practical value in training and medical schools' instruction, behaviorist model of learning (The operant conditioning), the ideas of John Dewey relevant to training and instruction, constructivist learning theory, Jean Piaget's cognitive theory, the practical applications of Jean Piaget ideas in training and instruction, Lev Vygotsky ideas' practical application in training and instruction including the zone of proximal development, the concept of Instructional scaffolding suggested by Jerome Seymour Brunerm, the fundamental principles of learning relevant to training and medical schools' instruction, the fundamental principles of learning relevant to training and medical schools' instruction, the principles of Adult learning (Andragogy) suggested by Malcolm Shepherd Knowles, the principles of the constructivist's approaches for adult training and instruction, the main principles of adult training and instruction that distinguish adult learners from children and youth, the principles of making presentation, what a TOT course is all about and he need for TOT courses.

\section{Discussion}

\section{Accreditation of a training course}

Accreditation of a training course occurs when an independent scientific body evaluates a training course, the training methodology used in the course, and the qualifications of the trainers and lecturers of the course and approve the course. Unaccredited courses are now generally recognized as a waste of time of resources $[1,2]$.

\section{The need for professional training}

Training and development as a discipline falls into two main categories or levels:

a. Personal training and development.

b. Training and development in an organization which is generally called human resource training and development.

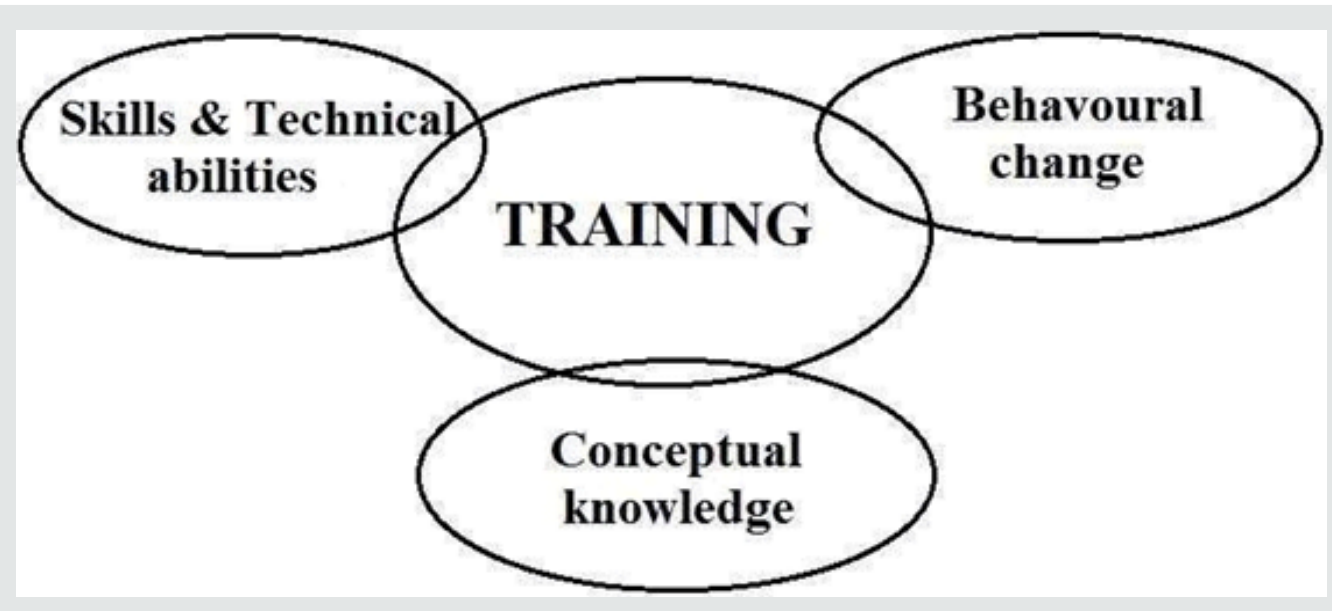

Figure1: Domains of the change during training.

The importance of professional training and development has become well recognized and accepted by many organizations and institutions. Training and development are considered by some organizations as an investment and not an expense because of its rewarding influences. Figure 1 shows why Training and development is considered by some organizations as an investment and not an expense. Training and development are commonly used as an organization investment in its own cadre enables the organizations to surpass their competitors. For example, a study published in the British Journal of Surgery concluded that 
after the initial training period, laparoscopic cholecystectomy is less expensive than the open operation and represents a costeffective method for treatment of patients with gallstones [3]. However, when training and development programs don't follow the accepted scientific principles and cannot be accredited, it becomes unnecessary burden and a source of distraction $[3,4]$. Better performance is associated with training and is generally attributed to the fact that properly trained professionals are more capable of meeting the job expectations than the untrained professionals $[3,4]$. In addition, training helps the organization in reducing redundant works which reduces performance. Training and development are also considered by some organizations as a retention tool for the employees and professionals as they will perceive training and development as a commitment from the organization [3,4]. Professional training and development help in the creation of learning and creative environment and fostering creative thinking which help the organization or institution to find solutions to problems. However, despite all the benefits associated with training, there is no point in training just for the sake of training or training everyone in the organization or institution without considering what the organization or institution is trying to achieve and how training and development programs help in achieving organizational goals [5]. For example, if a hospital found a high rate of infection, it may be considered that infection control training is required for a certain number of selected staff whom training is expected to help in controlling the rate of infection in the hospital and reduces the extra-expenses. In healthcare organizations, training is considered to be an important factor in the reduction of medical errors. Understanding the principles and concepts of training, development, and the related concepts and disciplines has become necessary for doctors practicing at almost any level because of:

a. The increasing complexity of medical care environment, and medical education and practices.

b. Physicians particularly consultants are frequently placed in teaching and training positions.

c. Many doctors are responsible for the training and development of employees who are not doctors such as nurses, allied health professionals, and other management employees $[3,4]$.

Professional training is an activity that is focused on and evaluated against the job that an individual hold. When doctors are graduated from medical schools, they have the knowledge, but they lack the skills. Training during rotation residency is a classic example of professional medical training that aims at providing the participants the basic skills they need to perform their job or developing new skills $[3,4]$, [6-8].

Development training is an activity that focuses on the activities that individuals in an organization or institution may participate or contribute to in the future. Developing a doctor to be a trainer in a certain field may demand enrollment in a development course called training of the trainers course (TOT).
Developing a doctor to be instructor in a university may demand enrollment in a development course called instruction methods. Developing a doctor to be a hospital manager or director demands enrolling him in a hospital management training course or courses. Developing healthcare professionals to be more understanding of the healthcare environment and more capable of adapting to the continuously changing healthcare environment and to enable them to be more creative may demand enrolling them in a medical leadership and healthcare leadership training course or courses $[3,4],[6-9]$.Development training must support the organization's strategic goals. For example, if one medical organization's goal is to enable employees and professionals to have higher certificate in an other countries, training in multiple languages can help the achievement of this goal. If a hospital has a goal of attracting patients (clients) from other geographic regions, again training the employees in multiple languages can also help the achievement of this goal $[3,4]$, [6-8]. The need for the acquisition of new knowledge and skills to enable organizations the provision of modern sophisticated services, and ultimately making the services equivalent to the services provided by similar contemporary organization throughout the world, led to the emergence of the concept of continuing professional development, and consequently the development of continuing professional development programs which are also called continuing professional education programs. The need for the acquisition of new knowledge and skills to enable organizations the provision of modern sophisticated services is one of the important cornerstones of any continuing professional development program. The other cornerstone of any professional training development program is the access to an independent scientific professional body or committee to establish accredited training activities or to evaluate and accredit the already exiting training activities. The presence of suitable incentive that encourages professionals to join the training and development activity which provides the knowledge and skills needed by the organization is another important cornerstone of any professional development program. Training and development centers have been established in many universities and national departments (ministries) with the main aims and functions of establishing or supporting the development of accredited training and development activities, and also developing a well-qualified trainers capable of working efficiently within the training and development system who are capable of designing and conducting training and development activities [3-11]. The required scientific and professional activities for professionals cannot be determined by training and development centers. In the case of healthcare professionals for example, the required scientific and professional activities should be determined by colleges of medicine, nursing, and dentistry; professional associations of medicine, nursing, and dentistry; and specialization boards [3-8].

Training and development in a healthcare organization Professional training of residents in rotation is generally the responsibility of hospital administration and hospital departments and sections. Professional training of general practitioners is generally the responsibility of the medical association, and in 
some countries like Iraq should be arranged by health sectors and directorate affiliated to the department (ministry) of health. Professional training of specialty residents is generally the responsibility of the boards of medical specializations and hospital departments and sections. Development training is generally the responsibility of training and development centers [3,4].

\section{Domains of Change During Training}

Change generally occurs in three domains during training (Figure 1):

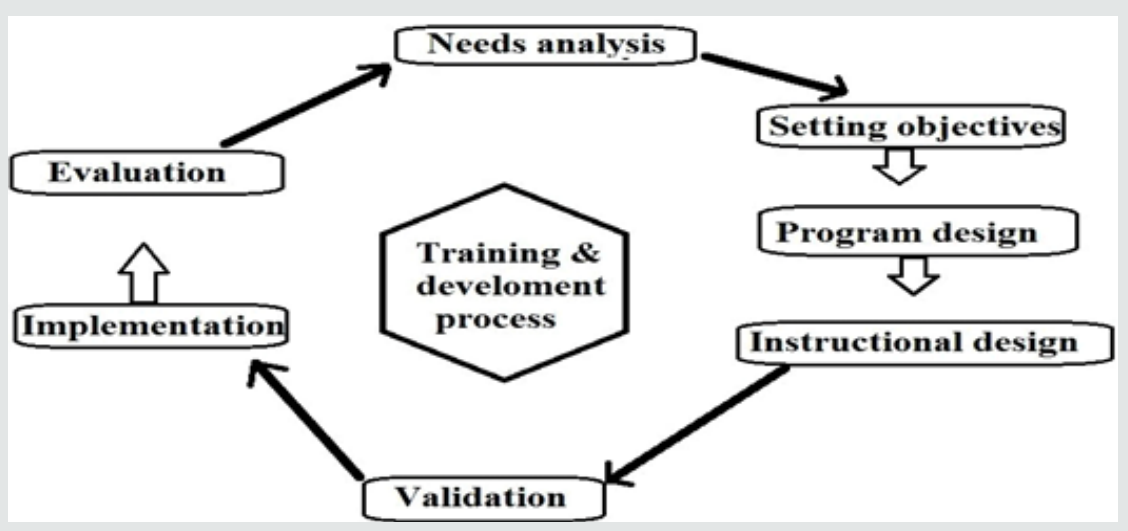

Figure 2: Domains of the change during training.

Table1: The influences of professional training and development $[2,3,4,12]$.

1-Better utilization of employees' and professionals within the organization and improvement of employees' job knowledge and skills, and professionals technical and behavioral skills.

2-Help the employees and professionals within the organization in attaining personal growth.

3-Expand the horizons of human intellect and the overall personality of the employees and professionals within the organization.

4-Improve the productivity of the employees and professionals within the organization.

5-Indoctrinate the sense of teamwork, team spirit, and inter-team, and enhance enthusiasm to learn in the organization.

6-Help in creating a learning culture within the organization and building positive perception and feeling about the organization.

7-Improve the quality of work and services.

8- Improve the morale of the employees and help in creating healthy working environment and building good relationship within the organization.

9-Help in aligning the employees' goals with organizational goals.

10-Improve the health and safety of the organization.

11-Help in creating a better shared image.

12-Improve profitability leads to positive attitudes towards profit orientation.

13-Increase organizational decision making and problem solving.

14-Help in understanding and carrying out organizational policies.

15-Improve leadership skills, motivation, loyalty, better attitudes.

16-Keep employees on the cutting edge of knowledge and practice.

Table 2: The training process $[2,3,4,12]$.

\section{A-Stages of the training process}

1-Needs analysis: Needs analysis involves identification of training needs for the employees in an organization.

2-Setting SMART training objectives.

3-Training program design.

4-The design of instruction and training methods used during training.

5-Validation of a training course or program by accreditation.

6-Implementation of the training course or program.

7-Evaluation of the training course or program.

\section{B-Training needs}

Citation: Aamir Jalal Al-Mosawi. Essential Training Knowledge for Physicians Working in the Field of Professional Training and Development, and Medical Schools' Instruction. Res \& Rev Health Care Open Acc J 4(3)- 2019. RRHOAJ.MS.ID.000187. DOI: 10.32474. RRHOAJ.2019.04.000187. 
1-Task analysis: Task analysis involves assessment of new employees training needs. Task analysis is performed by a detailed study of a job to identify the specific skills required. The minimum skill requirement for each role needs to be determined to facilitate establishment of a specific training curriculum.

2-Performance analysis: Assessing current employees training needs.

\section{C-Training needs analysis methods}

1-Interviews and feedback from colleagues.

2-Competence or knowledge tests which test job knowledge and skills.

3-Observing work taking place: Observations usually made by supervisor or high rank advisor.

4-Appraisal documents or curriculum vitae.

5-SWOT analysis (Analysis of STRENGTHS, WEAKNESSES, OPPORTUNITIES, and THREATS) can be used for identifying the needs of individuals and groups. It is considered a good technique for helping employee to identify their own training needs.

\section{D-Setting SMART training objectives}

SMART training objectives make training evaluation and review much easier. [ Specific objectives that explain the required tasks, Measurable objectives enable determining tasks completion by measuring the realization of the desired goal, Achievable objectives in term of resources and time, Realistic objectives at appropriate level and relevance to the development of the employee, Time-bound objectives with appropriate deadlines scheduled reviewing process].

Table 3: Designing an effective training course $[3,4,13,14,15]$.

1-Making learning meaningful

Meaningful materials are easier to understand and remember. Training and instruction materials can be made more meaningful by:A-Providing an overview of the materials to be presented at the start of training and this is usually achieved by providing the syllabus of training.

B-Distributing a printed paper summarizing the general ideas of the training materials (Handouts and worksheets).

C-The use of familiar examples.

D-Organizing the presented information logically.

2-Making the skills trained in the course easily transferable to the work site

A-Maximizing the similarities between training environment and work circumstances.

B-Providing a time for adequate practice. People learn better by doing, therefore; it's important to provide practice as realistic as possible.

\section{3-Motivating the learner}

A-Explaining why training is important and how it will benefit the trainee.

B-Reinforcing immediately correct responses during training.

Table 4: Popular training methods.

On job training: This training method is very appropriate for physicians during their residency programs, and also other health professionals such as nurses.

Lectures: lecturing is a commonly used simple method. Lecturing is most effective in achieving the objective of knowledge acquisition.

Audio-visual training: Training with videos and audiotapes has become increasingly popular. Training with video tapes is most effective in achieving the objective of participant acceptance followed by knowledge acquisition.

Simulated training

Distance and online training.

Other training methods include: case study, self-assessment, etc.

Table 5: Lecture preparation.

Organize the ideas of a lecture in advance by selecting a title that conveys clearly what the lecture is all about and giving an overview about the topics of the lecture with a concise overview of the new information presented during the lecture.

Relate new content to prior knowledge.

Organize and elaborate new information.

Reduce boredom by asking questions, inviting questions and allowing discussion.

Citation: Aamir Jalal Al-Mosawi. Essential Training Knowledge for Physicians Working in the Field of Professional Training and Development, and Medical Schools' Instruction. Res \& Rev Health Care Open Acc J 4(3)- 2019. RRHOAJ.MS.ID.000187. DOI: 10.32474. RRHOAJ.2019.04.000187. 
Table 6: What a professional trainer needs to understand and do before and during a training course development $[3,4]$.

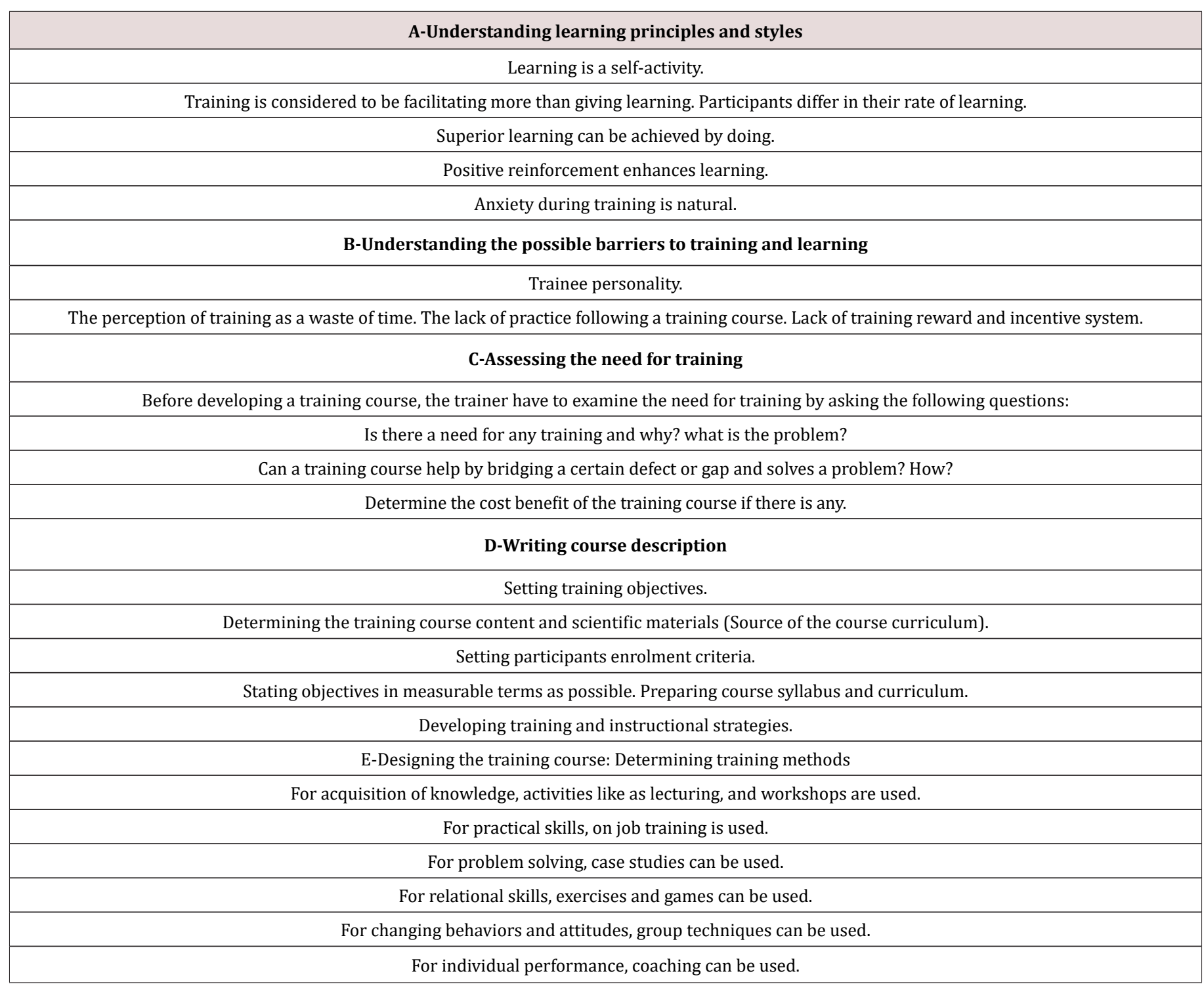

a. Conceptual knowledge: training is associated with gain in conceptual knowledge.

b. Skills and technical abilities: training is associated with acquisition of skills and enhancement of technical abilities.

c. Behavioral change: training foster positive attitudes and behaviors which is mostly by the transfer of learning to the workplace

Table 1 summarizes the influences of professional training and development. Table 2 summarizes the components of the training process. Figure 2 shows the cycle of the training and development process. Table 3 summarizes how to design an effective training course. Table 4 summarizes the popular training methods. Each of these methods has advantages and disadvantages. However, depending on the situation each method can be a valuable tool for teaching employees' new skills and behaviors. Lecturing is one of the most popular instruction and training methods. During traditional lecture, the trainer or instructor usually talks, and the participants listen with or without taking notes. During lecturing, training and learning materials can be covered easily and quickly. However, lecturing can be associated with lack of interaction and high likelihood of boredom. It is pity to observe many who lacks the experience of lecturing make a lecture by copying texts from books or other sources converting this training and instruction method of lecturing into something more like a book reading. Experts have suggested that instead of reading a text brought from books, articles and other sources, it will be more convenient and time saving to ask the audience to read the chosen text or article. Therefore, in order to avoid the unnecessary practice of book or article reading instead of lecturing, a lecture should include at least 10 references. For lectures in the field of applied sciences like medicine, at least seven of the references should be scientific journal articles and the use of books as a reference is preferably limited to three or less $[3,4]$. Table 5 summarizes how to prepare a lecture. Table 6 summarizes what a professional trainer needs to understand and do before and during a training course development 


\section{How to conduct a professional training course}

A training course begins by welcoming the participants and ice breaking activities followed by general introductory talks and some introductory modules. A training course is usually divided into training sessions; each of them includes several modules. It is important during the first day of a training course to clarify the main aims and learning objectives of the course and the main training methods used during the course, and also how assessments and tests are conducted during the course. The introductory modules in the first day of this course were about accreditation of a training course and the need for professional training. A training day should conclude by summarizing what happened during the day (Figure 3). In general, a professional trainer should always finish each training day by a conclusion remarks summarizing what happened during the day [12-15]. It also important that a professional trainer collect the participants feedback and remarks after each training day, and this can be achieved the participants the following questions:

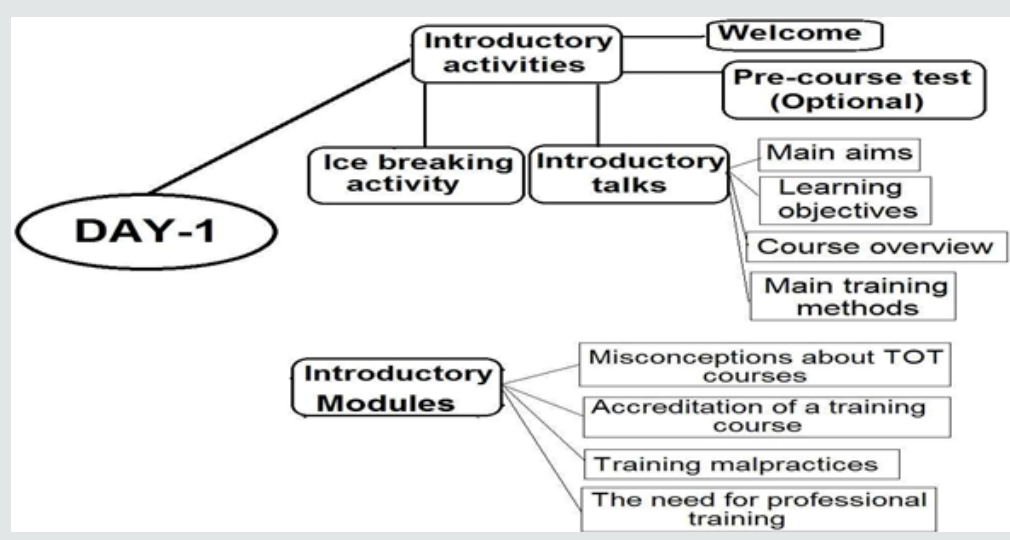

Figure 3: A training day should conclude by summarizing what happened during the day.

a. What is the topic that you liked most?

b. Is there a thing come to your mind and you want to learn more about it?

c. What is the topic that you didn't like?

Training evaluation is a continuous and systematic process of assessing the value or potential value of a training course, activity or event. When designing a training program, it is mandatory to consider the consequent need for evaluation. A training course or program should be designed against specific objectives and expected benefits. This design will enable evaluation of the successfulness of a training course against certain achievement indicators. Therefore, evaluation models are designed to make the progress of the training program clearly reflected through the periodical evaluations [3,4,16-18]. Table 7, 8 summarizes the main principles of training course evaluation. Figure 4 shows Kirkpatrick's four levels model. Table 9 summarized the evaluation of a training course using Kirkpatrick's four levels of evaluation.

Table 7: How to conduct a training course $[3,4]$.

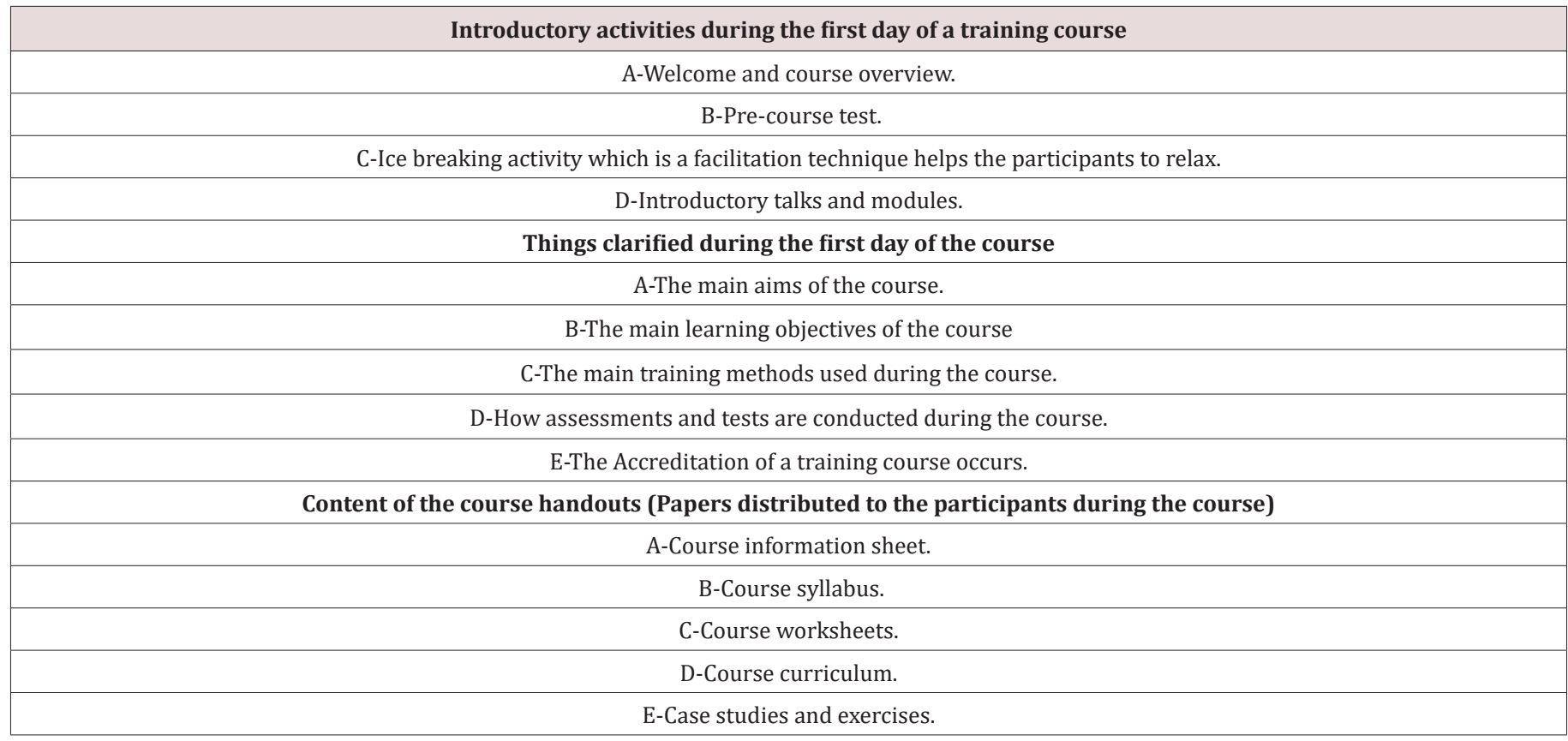

Citation: Aamir Jalal Al-Mosawi. Essential Training Knowledge for Physicians Working in the Field of Professional Training and Development, and Medical Schools' Instruction. Res \& Rev Health Care Open Acc J 4(3)- 2019. RRHOAJ.MS.ID.000187. D0I: 10.32474. RRHOAJ.2019.04.000187. 
Table 8: The main principles of training course evaluation.

\begin{tabular}{|c|}
\hline \multicolumn{1}{|c|}{ Early evaluation } \\
\hline Early evaluation of the outcomes of training after each training course should include: \\
\hline 1-Analyzing trainees perception of the value and usefulness of training. \\
\hline 2-Testing the trainees knowledge for the materials covered. \\
\hline Late evaluation \\
\hline Later evaluation of the outcomes of training is generally conducted few months after a training course should include: \\
\hline 1-Evaluating whether the trainees are using the skills and behavior learned on their job. This can be achieved through: \\
\hline A-Conducting a workshop or meeting for the participant where they can talk about how \\
\hline the course changed their practices or attitudes. \\
\hline B-Sending the participants a questionnaire form. \\
\hline 2-Evaluation of the effect of the training on performance improvement on job can be achieved by questionnaire form to the participant s superiors. \\
\hline
\end{tabular}

Table 9: Evaluation of a training course using Kirkpatrick's four levels of evaluation.

\section{Level -1 evaluation: Reactions/ Smile sheet evaluation}

Donald Kirkpatrick emphasized that all training courses and programs should at least be evaluated at this level to enable improvement of a training program. Participants' reactions have an important relation with learning. However, a positive reaction does not guarantee learning, but a negative reaction almost certainly reduces the possibility of significant learning achievement.

Reaction means how participants perceived the training and how they felt about the training. At this level, evaluation is in the form of feedback from the participants. It is a simple measure of the level satisfaction of the participants.

$$
\text { Did the participants like the training? }
$$

Did the participants consider the material relevant to their work?

\section{Level -2 evaluation: Learning}

This level involves assessing the amount of participants learning by measuring the acquisition of the content in term of gain in knowledge and skills, and if possible the change in attitude.

Ideally, learning evaluation is performed formally by conducting a pre- test (before training), and posttest (after training) and comparing the two tests performance.

\section{Level-3 evaluation: Behavior (Transfer of learning)}

This evaluation level involves assessment of the transfer of knowledge, skills, and/or attitudes from training to practice and workplace resulting in a change in job behavior due to the training course or program. This evaluation is usually conducted 3-6 months after training by observing the trainee in their workplace. Many trainers consider this level the most reliable assessment of training course effectiveness. However, it is very difficult to foresee when the change in behavior will occur to make final decisions regarding training effectiveness. Therefore, it is very difficult to determine the best time for evaluation, and how often evaluation should be performed.

\section{Level-4 evaluation: Result (outcomes of training)}

This level involves attempt to measure the success of training in term of service improvement, and reduction of errors. In business and manufacturing organization, the success of training is reflected on increased sales, production, and higher profits.

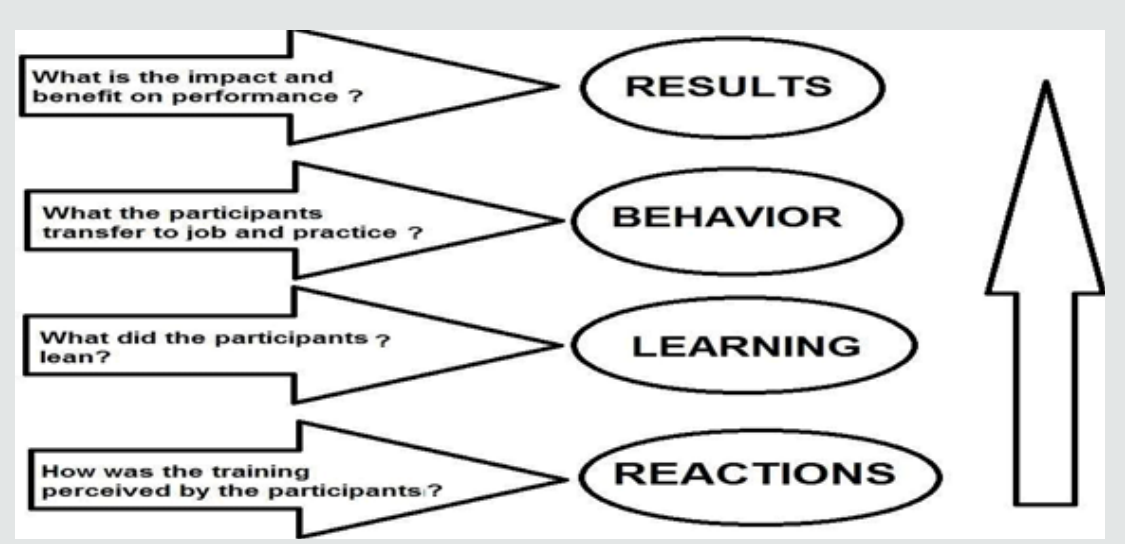

Figure 4: Kirkpatrick's four levels mode. 


\section{Instruction Methods}

An instruction method refers to the principles and methods used for teaching. Table 10 summarizes the methods of instruction and training.

\section{Training and instruction effectiveness}

Many factors affect the effectiveness of training and instruction including the trainer or instructor character, and participants characteristics such as individual interests, ability to meet course tasks. In addition to the characteristics of the course itself. The trainer or instructor cannot control all the factors especially when working as a part of a team. In some circumstances, the course materials, course outline and textbook are determined by a committee rather by the trainer on instructor. Instructors may teach in courses that are a part of a degree program in which certain objectives, determined by the institution granting the degree. The trainer or instructor is expected to try to maximize input into the controllable factors that influence training and instructional outcomes and, the assessment of training or instruction $[3,4]$. Table 11 summarizes the factors affecting training and instruction effectiveness. Table 12 summarizes the principles of training and instruction effectiveness evaluation.

Table 10: Commonly used methods of instruction and training [3,4,19,20].

\section{1-Lecturing}

Explaining or lecturing is the process of teaching or training by giving spoken explanations of the subject to be learned. Lecturing is often accompanied by visual aids to help learners visualize an object or problem. This method has the advantage of quickly delivering the materials but may be associated with lack of interaction.

Demonstration is the process of teaching through examples or experiments. It can be used to prove a fact through a combination of visual evidence and associated reasoning. This method is based on making impersonal experiences of memorization become a personal experience. It helps to raise participant s interest and reinforce memory retention because they provide connections between facts and real applications of those facts.

\section{3-Discussions}

Active learning process by talking with each other and listening to other points of view. In this training method, the trainer describes briefly a topic or problem and invites participants to comment. One of the advantages of this method is enabling the trainer to judge the interest of the participants in the topic and the opportunity to stimulate interest. However, discussions may not cover all the points intended to be covered and dominant participants may take over and don $t$ allow hesitant participants to speak.

\section{4-Training by teaching}

In this method, participants assume the role of instructor or trainer and teach other participants. Participants need to study and understand a topic well enough to teach it to their peers. This method helps in gaining self-confidence and strengthens participant s speaking and communication skills.

\section{5-Other training and instruction methods}

Games, role playing, group problem solving, brain storming, case study, simulation

Table 11: Factors affecting training and instruction effectiveness.

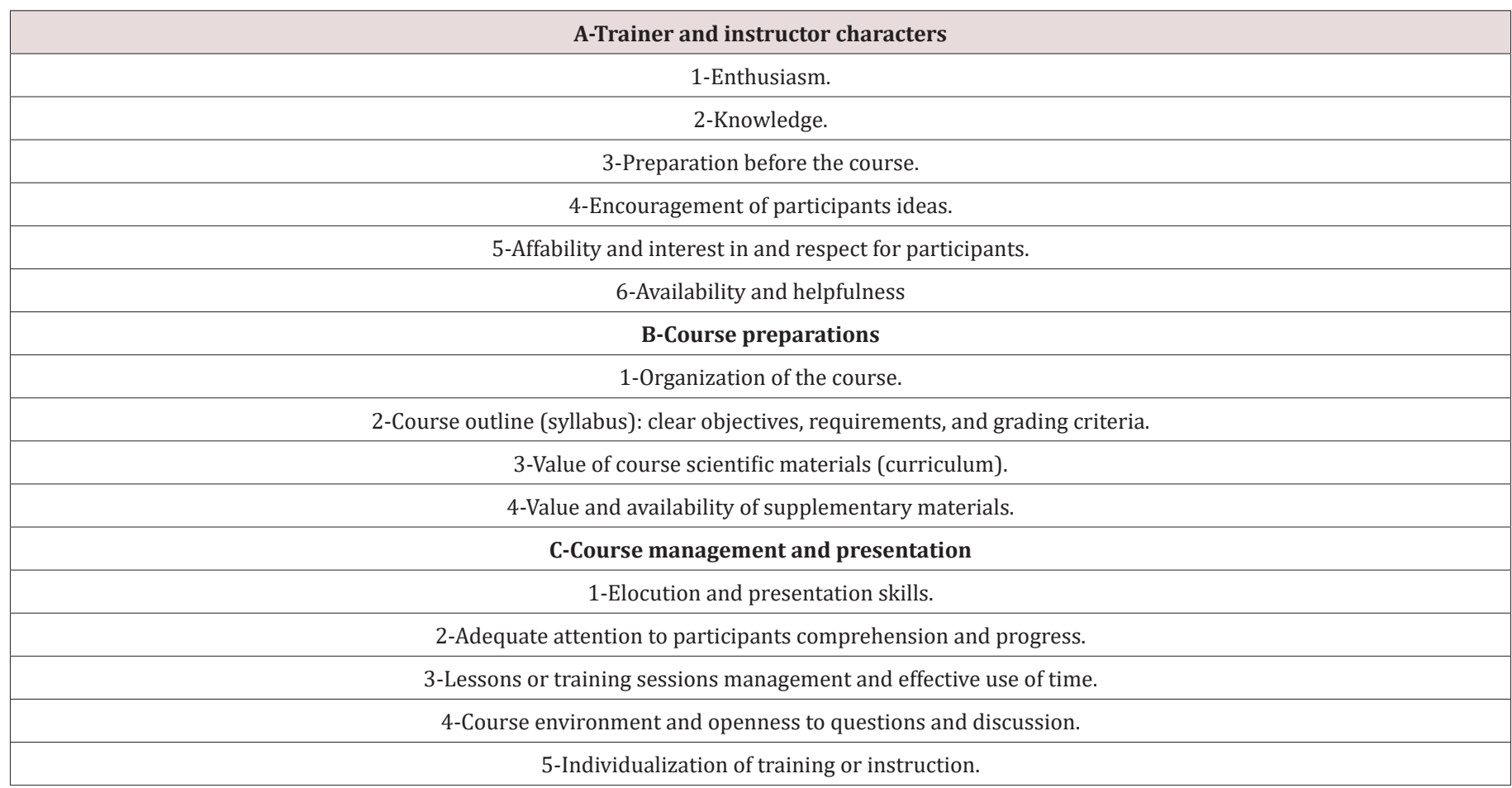




\begin{tabular}{|c|}
\hline 6-Adherence to course objectives. \\
\hline 7-Inspiration of interest in the course and its content \\
\hline 8-Motivation of participants. \\
\hline D-Assessment and tests \\
\hline 1-Evenhandedness and quality of the tests. \\
\hline 2-Unbiased evaluation of participants. \\
\hline 3-Diversity and frequency of assessment and tests. \\
\hline 4-Frequency of advice and feedback to participants. \\
\hline
\end{tabular}

Table 12: Training and instruction effectiveness evaluation.

\section{A-Formative and summative assessment}

The formative assessment is performed early during a course to give the trainer or instructor the opportunity to respond to suggestions for improvement. The formative method is sometimes conducted by the institution or organization arranging the courses, lectures or the training program.

The summative assessment evaluates the training or instruction at the end of the course and help the trainer or instructor in the future.

\section{B-Formal evaluation of training and instruction effectiveness}

In formal evaluation, there is official recording of the evaluation. Formal evaluation is generally made by the institution such the faculty or a training centre. Informal evaluation by peers' feedbacks and is not recorded.

C-Trainer or instructor self-evaluation: Trainer's or instructor's self-evaluation is generally considered of the formative type, as it enables change when the feedback is negative and also help in establishing personal strengths.

1-Trainer's or instructor's reflection and self-evaluation the trainers and instructors are expected to continuously reflect on the following points during self-evaluation:

1-The adherence to the course objectives in a timely manner.

2-The availability and presentation of evidence of learning

3-Participants ability to meet expectations and performance standards.

4-Regular communication with participants which gives a different dimension to self-evaluation.

2-Videotaping the lessons or training sessions: The trainer or instructor can study his or her mannerisms, gesture, facial expressions, reactions to participants questions, participants participation, etc. Analyzing the course video will help the instructor or trainer in improving the instruction and training, and the learning during the course.

\section{D-Peer evaluation}

The selected colleague for peer evaluation is someone who is respected as trainer or instructor and not perceived as professionally threatening. Peer evaluation can be a powerful aid to professional development and can help the instructor to understand that excellence in teaching is a short-lived phenomenon.

\section{E-Participants' evaluation}

Participants' input and feedback through interview or written evaluation form is used as a formal evaluation process in some institutions. However, some institutions do not conduct participants evaluation because of the risks associated with interpreting such evaluation include:

1-Participants may not bein a position to be able to judge answers to the questions being asked or to judge the professional competence of a trainer or an instructor.

2-Participants' perceptions of the trainer or instructor effectiveness are strongly related to their own course performance and grades.

3-Participants' evaluation to the trainer or instructor communication of the course content is related to attendance and preparation before the course.

4-Participants can misjudge the importance of essential activities that are necessary to meet the learning objectives of the course.

5-Participants' evaluation do not take into consideration how much effort they put into the course.

\section{Participants learning assessment during training and instruction}

Assessment is a diagnostic aid that helps in establishing effective instruction and training through measuring participants learning achievement. Participants learning needs cannot be met without regular assessment. In addition, participants learning assessments provide the participants themselves, the necessary awareness about what they understand and also about the gaps in their knowledge [3,4]. Diagnostic assessment facilitates designing training and instruction and help in determining the participants levels. Diagnostic learning assessments can be performed formally or informally. It usually performed at the beginning of training or instruction to determine the pre-training or pre-instruction learning, ability level and the learning needs of the participants $[3,4]$. Diagnostic assessment enables enhancement of instruction and training effectiveness through [3,4], Helping the trainer or instructor in developing an insight of the diversity of the participants learning ability and of the training and instructional needs of the participants. Facilitates making the necessary changes to training sessions or lessons to meet the needs of the learners. 
Formal diagnostic assessment usually includes tests, quizzes, or pre-tests. Informal assessment can be performed through:

a. Homework assignments.

b. Training sessions practice and activities.

c. Effective questioning techniques to determine depth of understanding of a concept.

d. Assignments designed to target certain skills.

Traditional summative assessment or the traditional assessment of learning usually performed as a test or exam at the end of a training course. Summative assessments are also useful in evaluating curriculum, or participant placement in more advanced courses.

Formative assessment is a part of training or instruction process which assesses participants learning and is performed early during a training course. Formative assessment is performed to develop an earlier understanding of the participants learning. It can be performed formally by conducting a quiz or informally through observation participants understanding during training sessions. Formative assessment discloses the gaps in participants understanding, thus enabling the trainer or instructor to make the necessary adjustment. It also facilitates participants awareness of the progress made and enable them focus on the next step $[3,4]$.

Formative assessment methods include [3,4]:

a. Formal assessment of tasks by monitoring of homework tasks, quizzes, presentations, performances, experiments, debates, etc.

b. Observation of learners practice, acquisition of new skill, and their work with a new concept.

c. Regular checks for participants understanding.

d. Trainer-participants meeting is considered very effective way of monitoring participants progress with additional advantage of enhancing the trainer-participants relationship.

e. End of session form measures the learned knowledge and uncovers possible knowledge gaps. Questions in the form my include:

f. What is the one most important thing you learned from this session?

g. What is the thing that gave you some difficulty?

h. What thing you would like to know more about it?

Learning process for trainers and instructors Learning can be defined as relatively permanent changes in behaviour, skills, knowledge or attitudes resulting from particular experiences. Learning can be cognitive, physical, social, or emotional.

Permanence is a cardinal feature of learning and temporary changes are not considered learning. Forgotten materials represent a lost change can't be regarded as being learnt.

\section{Teaching or Instruction Vs. Learning During a Training Course}

Teaching or instruction is the teacher s (instructor s or trainer s) efforts. Learning is what participants achieve from their efforts. Therefore, learning is not referring only to the experiences and what are encountered in training courses or lectures as important part of participants efforts may be achieved outside the training courses, lectures, etc. The training environment, and the number of participants in the course, can affect learning, and how training should be conducted. The learning materials are generally presented as curriculum content and the skills expected to be learned during the course. During the process of teaching in a lecture or a training course, an additional unintended learning may occur alongside the explicit learning of the official curriculum and is called incidental learning. This type of learning occurs without the trainer or learner deliberately trying to make it happen. The initial preparedness of the course participants or the lecture attendee to cope with or get benefit from the activities has an important influence on learning. The concept of readiness and preparedness is applicable not only to course participants and trainees, but also to the trainers and instructors who need to be ready and prepared to plan a training course. To ensure the permanence of change during a training course, it is important to transfer the taught materials to future practice. After the training course the participants should be able to use knowledge or skill in their real practice [19-24].

\section{VAK Learning Model}

People vary in their learning orientation. Learners' preferences originally divided into three common categories, referred to as the VAK model. According to this model, trainers and instructors have to use various approaches to engage all participants with various learning styles which include visual learning auditory learning kinesthetic learning

\section{Visual learners:}

prefer pictures, diagrams, and other visuals. They need to see something to know it and may have difficulty learning from lectures.

Auditory learners prefer to get information by listening. They need to hear something to know it and may have difficulty doing activities that include reading. Talking to the participants (lecturing) is more effective with such participants.

Kinesthetic learners prefer hands-on learning. They need to do something to know it. Many kinesthetic learners have the ability to assemble things without reading directions. Exercises and case studies are more effective with such participants [3,4,24].

\section{VARK learning model of Neil D. Fleming}

VARK stands for Visual, Aural, Read/write, and Kinesthetic sensory modalities that are used for learning information. Before Fleming's work, the VAK was used. Fleming added a fourth model by dividing the Visual dimension (the $\mathrm{V}$ in VAK) into two parts; Visual (V) and text as Read/write (R). Fleming designed the VARK model while working as an inspector for the New Zealand education 
system. Fleming thought that some eminent teachers could not reach some students while other less reputed teachers could. Therefore, he designed the VARK model based on his experiences, and work with students and teachers at Lincoln University.

Visual preference includes the representation of information in maps, diagrams, charts, graphs, flow charts, labelled diagrams, and all the symbolic arrows, circles, hierarchies and other methods that trainers and instructors could use to represent instead of words. Therefore, this preference style could can also be called Graphic (G) preference. The visual preference does not generally include real pictures or photographs, videos or PowerPoint. It includes designs, shapes and the different formats that are used to highlight and convey information. Drawing a diagram with meaningful symbols on a whiteboard is helpful for people with a visual preference.

\section{Auditory learners}

Have preference for information that is heard or spoken. Auditory learners learn best from lectures and group discussion.

\section{Read / write preference}

Learners need information to be displayed as words and text-based input and output (reading and writing) in all its forms including PowerPoint, handouts, articles, and assignments.

\section{Kinesthetic}

Means the perceptual preference of using experience and practice (simulated or real). Kinesthetic preference includes demonstrations, simulations, videos and movies of real things, case studies, practice and applications. Kinesthetic learners learn better by doing and performing activities, rather than listening to a lecture or watching demonstrations. Kinesthetic learners are generally known as "doers". Many learners are multimodal in their learning preference and have two, three or four almost-equal learning preferences $[3,4,21]$.

\section{The 4MAT learning model of Bernice McCarthy}

Dr. Bernice McCarthy from the United States developed the first basic structure of the 4MAT system in the late 1970s.Thereafter, the method has systematically and continuously been used and developed. The 4MAT model was developed with aim of helping trainers understand participants differences in their learning preferences, and how engage all participants by modifying the events of training or instruction based on understanding brain lateralization dominance and learning style to make training more attractive to each specific learner type. Bernice McCarthy suggested that the learning experience include two main parts: 1-Perceiving during learning occurs in two ways: Experiencing which is feeling and sensing the learning through experience. Conceptualizing which is thinking to translate the experience into the conceptual forms such as ideas and systems. The interaction between feeling the experience and thinking during conceptualization is important in connecting the personal values and perception of the participants to those of the trainer or instructor. 2-Processing what the learner perceived occurs also in two ways:

Watching and making sense of information and what the learner experienced through internal reflection.

Acting is making sense of new knowledge and information through external action and applying ideas by doing things and learning by practicing. Bernice McCarthy, thought that although most learners engage in many types of learning, they tend to prefer one of the four major types, and tend to ask a key question:

Imaginative learning involves largely feeling the learning experience, and seeking personal association, and making connections. Analytic learning practiced by thinker learner involves listening to and thinking about information. Analytic learners seek facts and think through ideas to learn what the expert think to formulate ideas. Common sense learning involves thinking, doing, experimenting, create usability, and applying ideas. Dynamic learning involves largely doing and seeking hidden possibilities experimenting and exploring. Learners learn by trial and error and self-discovery, and creating original adaptations [3,4]. Figure $5 \mathrm{~A}$ shows the types of learning preference styles according to the 4MAT learning model of Bernice McCarthy. Figure 5B shows Learner types key questions according to the 4MAT learning model of Bernice McCarthy. Figure 5C: The learning cycle according to the 4MAT learning model of Bernice McCarthy.

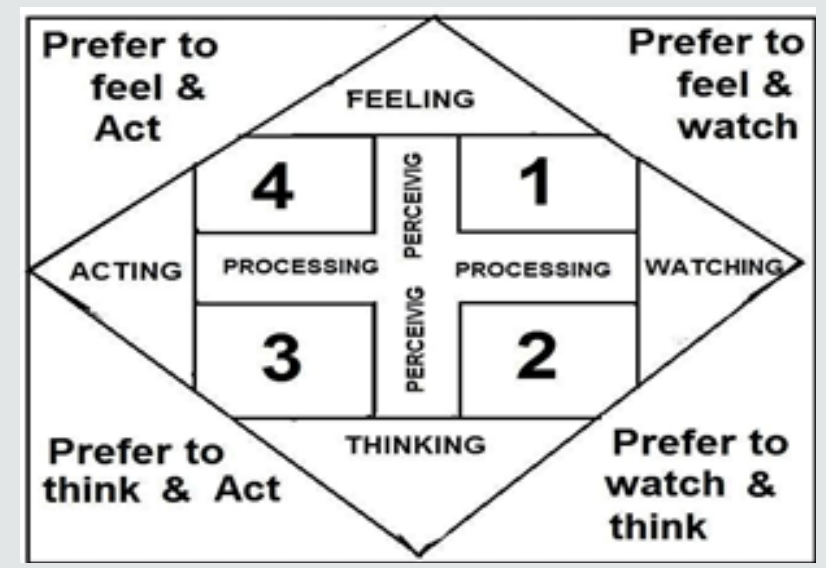

Figure 5A: Types of learning preference styles according to the 4MAT learning model of Bernice McCarthy. 


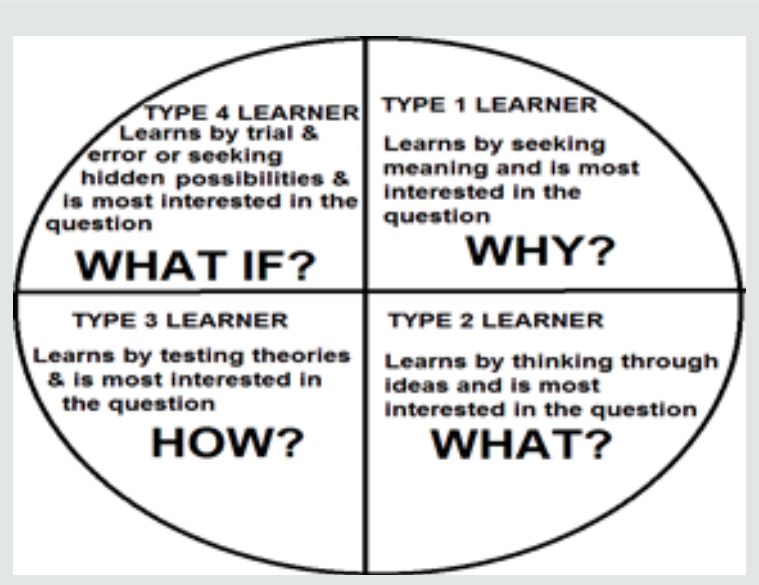

Figure 5B: Learner types key questions according to the 4MAT learning model of Bernice McCarthy.

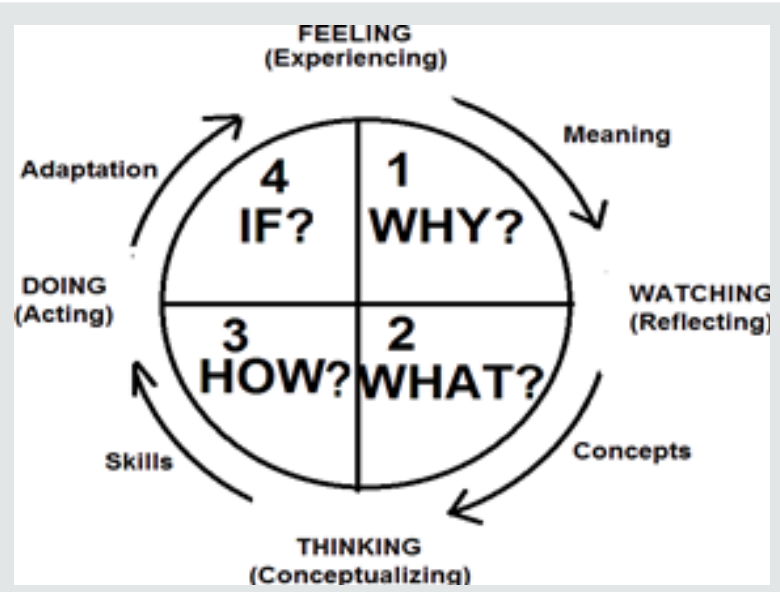

Figure 5C: The learning cycle according to the 4MAT learning model of Bernice McCarthy.

\section{The Application of Learning Theories in Training and Instruction}

Learning is a change in mental association and behavior due to certain experience. There are several theories of learning including theories of behaviorism, constructivism and cognitivism. Understanding learning theories enables the trainer or instructor to develop multiple perspectives into training and instruction. Therefore, learning theories are like multiple windows in a house that enables looking into the same room and get different viewpoints from each window [3,4,22-25].

\section{Cognitive learning}

Occurs through the acquisition of knowledge and skills by mental or cognitive processes and information processing. In cognitive learning, the participant learns by listening, watching, touching, reading, or experiencing and then processing and remembering the information. Cognitivism is a learning theory focusing on how information received, organized, stored and retrieved by the mind. Cognitivism views the mind as information processor. According to cognitivism learning theory, training and instruction should focus on achieving three goals: Understanding, Retention and Recalling. Cognitivism emphasizes that better retention and recall of information can be achieved through the use of a well-organized and sequenced training and instruction processes and presenting the information in understandable and meaningful ways. Better understanding can be achieved by activating prior knowledge by beginning the training session or training day by a review quiz and arranging the information into comprehensible parts that include pre- requisite knowledge and using graphics to help structure and relate contents. Retention of information can be improved with use of visual aids and mnemonics like SMART objectives. Cognitivism emphasizes that learning involves recall of stored information, and learning occurs when the learner can recall stored information $[3,4]$.

\section{Behaviourism learning theory}

Behaviourism theory of learning is based on making behavior changes in the learner by repetition and reinforcement. Behaviourism theory suggests that focusing attention on behavior instead of on thought during training or instruction with focusing on what the trainer wants the participants to do.

However, for a beginner (e.g. a medical student), focusing on the gains in knowledge (Cognitive approach) is necessary and it is more important to be able to describe how to perform the procedure 
than actually be able to do it. Therefore, it would be better to think of both approaches when planning training and instruction $[3,4,22]$. Constructivism theory of learning focuses on the inner thoughts of learners, and how they actively construct knowledge out of experiences. According to this learning theory, the training and instruction have to make learners actively involved in a process of knowledge construction as possible rather than passively receiving information all the time. Therefore, constructivist instruction encourages critical thinking, and creates motivated and independent learners that can build knowledge by doing.

\section{The main ideas of the constructivism learning theory include}

Using learner s prior knowledge schema to build upon is associated with more effective learning. In another word, the learners existing knowledge will be the starting point for new learning. Augmenting learning by making the learner actively engaged in the learning process rather than attempting to receive knowledge passively. Learning is best achieved by guiding problem solving [3,4,22-25]. The three major learning theories helped developing more theories that have more practical applications in training and instruction including: Descriptive theories that help in better understanding of learning. Prescriptive or instructional theories that prescribe or describe how to help people learn by suggesting methods to improve learning [3,4,22-25].

\section{The cognitive (knowledge-based) domain of learning and training and Bloom's taxonomy}

The cognitive domain of learning has been the primary focus of the majority of traditional training and instruction. It is frequently used to structure curriculum learning objectives, assessments and activities. The cognitive domain of learning and training was originally suggested by Benjamin Samuel Bloom, who was the chair of the committee of educators who proposed taxonomy of educational objectives based on the classification of educational goals. They published the first volume of the standard text taxonomy of educational objectives. The taxonomy aimed at promoting higher thinking in education such as analyzing and evaluating. In 1956, Bloom edited the first volume of Taxonomy of educational objectives: the classification of educational goal. The publication described a classification of learning objectives (Bloom's taxonomy) which became an important tool for developing training and educational curriculum. In the original version of Bloom taxonomy, the cognitive domain classified thinking and learning into six levels that are associated with six levels of objectives that can be practically used to create learning objectives for a training course and instruction. In the 2001 revised edition of Bloom's taxonomy, the levels were a little different and included remembering, understanding or comprehending, applying, analyzing, evaluating, and creating rather than synthesizing the six cognitive levels are generally hierarchical and begin with lower order thinking skills to higher order thinking skills. Learning on higher levels generally demands gaining prerequisite knowledge and skills at lower levels. Bloom's taxonomy can be used as backbone of training and instructional materials. and trainers can used it as a container for teaching and teaching skills. The taxonomy emphasized higher order thinking of analysis, evaluation, synthesis and creation. Bloom's taxonomy can also be used as a tool to help balance assessment and evaluative questions in class, assignments and texts to ensure all sorts of thinking are practiced during training [3,4,26,-32]. Table 13 summarizes the six levels of objectives of Bloom's taxonomy. Table 14 summarizes the practical value of Bloom's taxonomy in training and instruction.

Table 13: The six levels of objectives of Bloom's taxonomy.

Remembering involves retrieving, recognizing, and recalling knowledge (facts, terms, basic concepts, or answers) for long term memory without necessarily understanding their meaning. Remembering is necessary in acquiring:

Knowledge of specifics such as terminology, and specific facts. Knowledge of classifications and categories.

Knowledge of the universals and abstractions in a field such as principles and generalizations, theories and structures

Understanding or comprehending involves constructing meaning of facts and ideas from oral, written, and graphic messages. Understanding can be shown by the ability to interpret, explain, infer, compare, and summarize by organizing the main ideas.

Applying the learnt knowledge (facts, techniques and rules) in solving problems in new conditions. For example, using the knowledge to answer questions like Would lemon prevent scurvy, a disease caused by a deficiency in vitamin C?

Analyzing information by dividing it into parts, and determining how the parts are related, identifying causes, and making inferences and finding evidence to support generalizations.

Evaluating involves: Making judgments based on criteria and standards. Presenting views and opinions and supporting them by analyzing information and the validity of ideas, or quality of work based on a set of criteria.

Synthesizing or creating a structure or pattern from diverse elements by putting parts together to form a whole synthesizing involve making a unique message or statement, making a plan, or proposed set of operations, and concluding a set of abstract relations 
Table 14: Practical value of Bloom's taxonomy in training and instruction.

The participant needs to remember the concept before being able to understand it, and needs to understand the concept before being able to applying it.

The participant needs to analyze the concept before being able to be evaluating it.

The participant needs to thoroughly evaluate a concept before being able to create an accurate conclusion.

When introducing new concept, the participants need to understand, remember and apply the concept before moving to the higher order skills such analyzing, evaluating, and creating.

The cognitive domain levels help the trainer or instructor to write measurable and observable learning objective statement to describe what the participants will be able to do at the end of a module, training session or instruction unit.

Bloom's taxonomy provides a framework or context to organize training or instruction objectives.

\section{Behaviorist model of learning (The operant condition-} ing)

Burrhus Frederic Skinner was probably the first to bring the attention to the similarities between operant conditioning in the original research on tame laboratory rats and operant conditioning in humans. According to Skinner s ideas it is possible to strengthen desired behavior using operant conditioning. Operant conditioning is a learning process associated with likelihood that a specific behavior is increased or decreased through positive or negative reinforcement whenever the behavior is made; in result the individual associates the satisfaction or dissatisfaction with the positive or negative reinforcement. During training operant conditioning begins with the idea that certain consequences tend to make certain behaviors happen more frequently; e.g. if a trainer or an instructor compliments (reinforcement) a participants for a useful comment made (The operant or the learned behavior) during a discussion, there is more chance for more comments to be made in the future. Accordingly, The participants can be motivated and encouraged by giving a strong reason to do the desired action or to accomplish something. Skinner has been respected for suggesting what was considered a much- needed scientific approach to the study of human behavior. However, he has also been criticized for applying findings based largely on animal experiments to human behaviors.

\section{Skinner's operant conditioning is considered the most common version of behavioral motivation approaches}

Reinforcement is the fundamental concept of behaviorism, and it is considered the primary process that forms and controls behavior. Positive reinforcement is the strengthening or reinforcement of behavior by the occurrence of an event or action such as praise after a behavior. Negative reinforcement is the strengthening or reinforcement of behavior by the removal or avoidance of an unwanted event or experience. The behavior of using an umbrella is negatively reinforced by the cessation of rain. Skinner thought that human actions are affected by results of previous actions, events or experiences. Therefore, if a previous a behavior resulted in an undesirable outcome, the behavior will not be repeated. Whereas, if a previous behavior resulted in a desirable outcome, the behavior is likely to occur again in the future. Reinforcement is more effective if it comes immediately after certain operant behavior. For example, the behavior of making a useful comment during a training course is more likely to be reinforced by immediate praise. Operant conditioning affects motivation by encouraging intrinsic (internal) motivation, to the extent that the reinforcement for an activity is the activity itself. For example, when a learner reads a book for enjoyment of reading alone, he is reinforced by the reading itself, and reading is considered to be intrinsically motivated. Operant conditioning is not relevant to all forms of learning. According to Skinner s ideas, effective training and instruction may be based on positive reinforcement which he considered more effective at changing and establishing behavior than punishment. Trainees and learners learn mainly from being punished is how to avoid punishment. For example, if a trainee or a learner is forced to practice something, practicing will be associated with punishment and thus learns to hate and avoid practicing that thing. Trainers and instructors can modify trainee's behavior, and failure of training and instruction could be attributed to the lack of trainer or instructor an in-depth understanding of training and learning $[3,4,33,34]$. Skinner's ideas in training and instruction suggested that Without having adequate knowledge of the science of training and instruction, inappropriate methods and procedures can be used including $[3,4,33,34]$, The use of techniques that may lead to escape and avoidance and undesirable emotional effects. Relying on telling and explaining. Failure to assign learning tasks and to provide positive reinforcement adequately.

\section{The ideas of John Dewey relevant to training and instruction $[3,4,35]$}

a. Learners learn primarily by building on their own knowledge.

b. Instructors and trainers should design and modify the curriculum to fit participants prior knowledge and interests.

c. A curriculum needs to focus on the activities and responsibilities that a course participants or learners will practice in the future.

\section{Constructivist learning theory}

Constructivist theory or constructivism is a learning model suggests that participants can learn through guided experiences and reflecting upon those experiences. The participants are encouraged to actively engage in the process of learning to develop knowledge. The process is more democratic and participants centered. Trainers take the role of facilitator, rather than lecturer. In the constructivism model, trainer's main role includes promoting critical thinking and create independent learners who develop their own understanding of new knowledge. Models of constructivist 
learning theory differ about how much a learner constructs knowledge independently, compared to how much they take. However, all models of constructivist learning focus on learner's thinking rather than learner s behavior, but they have distinctly different implications for training and instruction. There are two main varieties of constructivism; psychological constructivism and social constructivism. Psychological constructivism and social constructivism suggest different approaches for effective instruction and training most effectively. Psychological constructivism emphasizes the independence of learner's thinking, while social constructivism gives attention to learner s need for social connections while learning. The main idea of psychological constructivism is that learning is achieved by mentally organizing and reorganizing new information or experiences. The organization occurs partly by relating new experiences to prior knowledge that is already meaningful and well understood $[3,4]$.

\section{Jean Piaget's cognitive theory}

Jean Piaget described learning as interplay between two mental activities called assimilation and accommodation. According to Piaget, assimilation and accommodation work together to enrich thinking and to create cognitive equilibrium. Assimilation is the interpretation of new information in terms of pre- existing concepts, information or ideas. Accommodation is the revision or modification of pre-existing concepts in terms of new information or experiences. It occurs alongside assimilation. Piaget ideas suggested the occurrence of two types of adaptations during learning. Assimilation is learner's response to a new event based on an existing schema, and in accordance with individual needs or conceptions. Accommodation is learner's modification to an existing schema or learner s formation of a completely new schema to deal with a new experience or event. Cognitive equilibrium is a balance between reliance on prior information and openness to new information. It consists of an ever- growing collection of mental representations for objects and experiences. Piaget called each mental representation a schema. A schema is a concept accompanied by an elaborated mixture of vocabulary, actions and experiences related to that concept. A schema is the mental framework of structured cluster of concepts that is created as a result of the interaction with physical and social environments. Schemata are: Critically important building block of conceptual development. Constantly in the process of being modified or changed. Modified by on-going experiences. A generalized idea usually based on experience or prior knowledge.

\section{The practical applications of Jean Piaget ideas in training and instruction}

According to Piaget ideas, instruction and training have to be learner-centered and constructivist to some extent with understanding that participants are adding new concepts to prior knowledge to construct or build understanding. Piaget ideas suggested that trainers and instructors have to consider the learners individual qualities and attitudes during curriculum planning, and add learners thought into the curriculum. Piaget ideas also suggested that trainers and instructors have to nurture and sustain learner's curiosity and involve learners' emotions and create a learning environment which makes participants feel safe. According to Piaget s work and ideas, participants can learn by expanding their knowledge and experiences accumulated from infancy to adulthood which are necessary for learning $[3,4]$.

\section{The theories of Dewey and Piaget became part of the movement of progressive education}

The thoughts of Dewey and Piaget played crucial role in the development of informal education. Dewey's ideas suggested that instruction and training must connect with and enlarge experience and thus instructors and trainers have to take the role of exploration of thinking and reflection [3,4,35]. Table 15 summarized John Dewey ideas about trainers and instructors' qualities. Social constructivism (or socio-cultural theory) emphasizes the importance of the relationships and interactions between a learner and the instructors and trainers who are more knowledgeable or more experienced. The social constructivist theory suggests that learning is like assisted performance. During learning, knowledge or skill from the expert who is skilled and motivated to teach and train can arrange experiences of the learner to allow the learner to practice crucial skills or to construct new knowledge [3,4], Lev Vygotsky suggested that learner's thinking is influenced by relationships with the more knowledgeable or expert and constructs knowledge better with social interaction with more knowledgeable and expert people. Vygotsky called the difference between what the learner can do alone and what cannot do without assistance, the zone of proximal development (Figure 6).

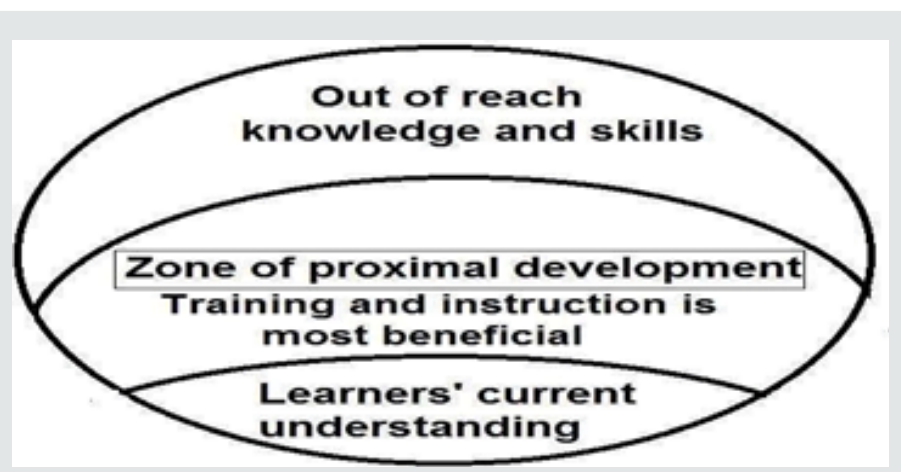

Figure 6: Vygotsky called the difference between what the learner can do alone and what cannot do without assistance, the zone of proximal development.. 
Table 15: John Dewey ideas about trainers and instructors qualities.

\section{There are scholars who have [the knowledge] in a marked degree but who lack enthusiasm for imparting it. To the natural born teacher learning is} incomplete unless it is shared

A trainer or instructor should have the inclination and passion for intellectual growth and a natural desire to communicate knowledge with others.

It is not enough for a trainer or instructor to be a lifelong learner of the techniques and the science of training and instruction. A trainer or instructor should always aspire and seek to share what knows with others in a learning community.

A trainer or instructor should have the ability to observe and respond to the movement of the mind with sharp awareness of the signs and quality of the responses the participants exhibit about the training and instruction materials.

Trainers and instructors who have never studied the art of instruction, but they were extraordinarily good instructors. Dewey explained that such trainers or instructors have a quick, sure and persistent sympathy with the operations and processes of the minds they are in contact with.

Good trainers or instructors who didn't study the art of training or instruction have a natural and genuine awareness of the complexities of mind to mind transfer, and have the intellectual strength and determination to recognize the successes and failures of the mind to mind transfer process, and how to appropriately repeat or correct it in the future.

Dewey s ideas suggested that a trainer or instructor personal inherent qualities are the most important attributes of good trainer or instructor as the acquired pedagogical skill cannot totally compensate the deficiency of the personal traits needed to be most successful in the profession of training and instruction.

\section{Lev Vygotsky ideas' practical application in training and} instruction included $[3,4]$

a. Learning should begin by focusing on fields within learners' zone of proximal development where training or instruction is most beneficial because it is just beyond participants current level of capability. With progressive learning the zone of proximal development will expands allowing the learners to handle progressively more complex topics.

b. If learning continues within learners' zone of proximal development, boring will ensue because the learners experiencing things that can do or learn independently and cannot perceive the need for training or instruction.

c. If the trainer or instructor begins training or instruction with contents that are difficult to achieve even with assistance, the learners will give up, and there will be a negative impact on the learner's self-confidence.

d. The people who help others learn should be more knowledgeable and expert to be capable of providing the necessary support and the social interaction which is believed to affect high order thought processes.

\section{Instructional Scaffolding}

Jerome Seymour Bruner thought that learners could usually learn more than was traditionally expected as long as they were given appropriate guidance and resources. Instructional scaffolding is the phrase that Bruner used to describe the support that learners should be given as they learn. Instructional scaffolding literally means a temporary framework like the ones used to construct buildings, which allows a much stronger structure to be built within it. Bruner emphasized the importance of providing guidance in the proper way and at the appropriate time. When scaffolding is provided correctly, learners appear to be more competent and they learn more. Bruner's work also suggested that a learner is capable of learning any material provided that the instruction is organized appropriately. Scaffolding is the support needed to help participants in achieving the learning objectives including the interactions aimed at guiding learning. Scaffolding is a strategy than can be used by experienced trainer or instructor to help less experienced participants when the experience difficulty. The process of scaffolding includes dividing learning into steps with the provision of guidance and monitoring. Guidance by providing step by step clear direction explaining what the participants have to do to achieve the objectives of a learning activity. Bruner also suggested the use of the spiral curriculum, an instruction approach in which each subject or skill area is revisited at intervals, at a more sophisticated level each time. First there is a basic knowledge of a subject, and then more sophistication is added, reinforcing principles that were first discussed. Bruner emphasized that learning is stimulated by creating interest in the material rather than by tests or punishment. Learners learn best when the presented knowledge are interesting $[3,4]$. Table16 summarized the fundamental principles of learning relevant to training and medical schools' instruction.

Table 16: The fundamental principles of learning relevant to training and medical schools' instruction.

\begin{tabular}{|r|}
\hline 1-The main purpose of training is to facilitate learning. \\
\hline 3-Learning is an active continuous process associated with learner's experience resulting from an interaction with the environment which is expected \\
to bring about a change in behavior.
\end{tabular}


8-Learning during training is considered as a process of changing behavior with experience.

9-Trainees during a training course are not just simply taught, but they should become motivated to seek new knowledge, skills and behaviors.

10-Learning during training may involve changing ways of believing, thinking and acting. Therefore, learning is not always a pleasant experience for a learner.

11-Trainees background of knowledge and experiences are affluent resource for problem solving and learning.

12-Trainees tend to adopt their individual ways of learning and solving problems. However, when Trainees are exposed to other s methods, they may refine their ways to become more effective.

13-Learning during training is an emotional and an intellectual process.

14-Learning during training is maximized when the trainees understand and express what they think and feel.

15-Learning during training should be interactive and mutually dependent.

16-Learning during training is a cooperative and collaborative process.

17-Trainer s roles in facilitating training include:

A-Encouraging trainees to be active.

B-Clarifying to the trainees the personal nature of learning.

C-Accepting differences, recognizing the trainee s right to make mistakes, and tolerating trainees limitations and imperfection.

D-Encouraging self-openness and self- trust.

E-Encouraging the learner s feeling of being respected and accepted. F-Accepting arguments.

Table 17: Principles of making presentation: The guiding principles of making presentation [2,3].

1-The trainer or presenter should try to know the audience and identify their interests before making the presentation or lecture. Planning relevant presentation requires understanding the interests of the audience from their profession, position, etc.

2-The trainer or presenter should reflect before the presentation about what the audience have to think and believe differently when they leave the presentation. This will help in making a plan to create the desired feeling and impression the participants will leave the presentation with.

3-The use of power point slides, videos and handouts. Presentations are preferably made with use of power point slides that include visual aids such as pictures or graphs and can be supplemented with videos and handouts. Handouts are mostly useful for complex presentation introducing new topic.

4-Creating a presentation content mostly follows the lecture preparation guidelines:

Organize the ideas of a presentation in advance by selecting a title that conveys clearly what the presentation is all about and give an overview about the topics of the lecture with a concise overview of the new information presented during the lecture.

Relate new content to prior knowledge.

Organize and elaborate new information.

5-Organize the message of your presentation logically:

A-Describe the problem.

B-Describe the effects.

C-Specify the need.

D-Propose a solution.

E-List benefits of the solution.

F-Sell its advantage.

G-Validate Claim.

6-Audience usually remember the first and last few minutes of a presentation. Therefore, a presenter should prepare a good opening summary and concluding remarks.

7-Create content to fill $\mathbf{7 0 \%}$ of the given time. This helps the presenter to find his/her pace and avoid being rushed. This practice will help also in focusing more on delivering the message of the presentation in appropriate ways.

8-Prepare the presentation to finish five minutes earlier. This is to avoid giving the image of clicking rapidly thorough slides and being preoccupied with your watch.

8-Handouts

A-The use of power point s visuals in handouts should be avoided as the best visuals make the worst handouts.

B-Include your contact information on the handouts.

C-Provide the necessary references which support the topic of the presentation. 
D-Prepare the handouts as a PDF file that can be e-mailed to participants when necessary.

9-Change the method of delivering the presented material every seven to eight minutes as possible. This is important to prevent habituation of the participants brains to the stimulus used. The presenter should try to avoid static delivery by using audio, video, stories, and other messaging vehicles to continuously change the stimulus and keeping the audience engaged and participative.

10-Reduce boredom by asking questions, inviting questions and allowing discussion.

11-The presenter should focus on rehearsal of the presentation more than practicing of the presentation. Practice is reviewing the slides while sitting in office. Rehearsal is the real practice of presentation while being up on feet, using the same gestures, eye contact, pacing and interaction which will be used in the actual presentation. During rehearsal spend adequate time on the invisible content of the presentation which is not present in the slides. The invisible content includes personal stories, analogies and explanation of slide text. The invisible content has a significant impact on presentation success as PowerPoint slide quality. Rehearsal can also be of formative benefits as it may help the presenter to modify the content of the presentation.

The presenter have to spend $30 \%$ or more of the practice time on the opening five minutes and concluding five minutes of the presentation, as these minutes are the time of establishing a connection with the audience.

\section{Conclusion}

This research article provided a compendium of the essential training knowledge needed by physicians working in the field of professional training and development (Professional trainers).The principles of Adult learning (Andragogy) suggested by Malcolm Shepherd Knowles Malcolm Shepherd Knowles was an American educator best known for using the term Andragogy to describe adult learning. According to Malcolm, Andragogy is the art and science of adult learning and it encompasses all forms of adult learning.

In Greek, andragogy means man leading. In Greek, pedagogy means child leading. Pedagogy is a teacher directed approach of instruction [3,4,36,37]. In 1980, Malcolm suggested four characteristics of adult learners that are different from the characteristics of child learners. In 1984, Malcolm suggested a fifth characteristic $[3,4,36,37]$.

\section{Self-concept}

Adults are autonomous and self-directed and need to be respected treated as self-directed individuals.

\section{Adult learners experience}

Adults have an accumulated and a growing amount of experience that becomes an important resource for learning.

\section{Readiness to learn}

Adults learners are oriented to their social roles and are goal and relevancy oriented.

\section{Orientation to learning}

Adults are practical and want to apply their knowledge. They also have the perspective of immediate application of knowledge rather than the postponed perspective of application of knowledge.

\section{Motivation to learn}

Adults have more internal motivation to learn (1984). They need learning to be enjoyable and gives them satisfaction. Adult learners also need to have a choice over what they learn.

In 1984, the ideas of Malcolm suggested four principles of adult learning that can be applied in instruction and training [3,4,36,37]:

a. Adults have to be involved in planning and evaluation of their instruction. b. Experience (including mistakes) provides the basis for the learning activities.

c. Adults are most interested in learning subjects that have immediate relevance and impact to their job or personal life.

d. Adult learning is problem-centered rather than contentoriented.

Malcolm's ideas practical applications in training and instruction include $[3,4,36,37]$ :

a. It is important to explain the reasons why specific things are being taught or trained.

b. Training and instruction should be more task-oriented instead of memorization.

c. Training and instruction should consider the differences of the participant s backgrounds, and use various training methods, instruction methods, learning materials and activities.

d. Adults are self-directed; therefore, training and instruction should attempt to make trainees discover knowledge with guidance and supervision without totally depending on the trainer and instructor.

Constructivist's approaches for adult training and instruction In essence, the constructivist viewpoint has two main ideas $[3,4]$ :

Knowledge is not given, but gained through real experiences, and the exchange of perspectives about the experience with others. Learned materials should have a purpose and meaning to the learner. Learning environment for adults based on constructivist approaches include a suitable design to make useful connections between new material and previous experience, through discovery.

\section{Therefore, constructivist training or instruction commonly involves strategies like $[3,4]$ :}

a. Asking open-ended questions such as How might this information be useful to you? to encourage participants to think about how new information may relate to their own experience. Participants responses to such questions are opportunities to realize the perspectives of others. Trainer or instructors should focus on materials that are useful for participants. 
b. Trainers and instructors try to train the required skills in authentic tasks as possible, and to create interest, and challenge learners to think.

c. Training and instruction include when possible practice in using imaginations to redefine problems from different perspectives.

d. Learning new information by building upon existing knowledge through the use of approaches such as case studies group projects, role play, and simulations as appropriate.

e. Trainers and instructors try to continuously assess the knowledge gained by participants and reconstruct learning error by filling in the gaps of participants understanding.

f. Trainers and instructor engage with the participants when they perform activities, and make comments, and ask the participants questions to promote reasoning.

The main principles of adult training and instruction that distinguish adult learners from children and youth are $[3,4]$ :

a. Adults learn only when they are internally motivated to learn.

b. Adults are practical and learn only what they feel they need to learn. 3-Adults learn better by doing, and active participation.

c. Adult learning is problem-based, and these problems must be realistic. Adult like to learn finding solutions to their problems.

d. Adult learning is affected by their prior experiences.

e. Adults learn best informally, and when they feel they need to know, whereas children learn from a fixed curriculum.

f. Adults demand guidance, and information that contribute to improving their situation.

\section{What a TOT course is all about}

A TOT course is the first step of developing a professional trainer and providing them with the necessary knowledge and skills during a TOT course. A professional trainer needs adequate knowledge about the principles of training and development, and also adequate understanding of the training process in an organization and how to manage training. The skills needed by a professional trainer include the ability to establish a training program and to conduct a training course successfully.

\section{The need for TOT courses}

The job description of many professionals includes training others, but the professional education of the job holder doesn't include the principles of training and how to conduct training courses. For example, a board-certified consultant physician is a well-qualified physician and has the responsibility of teaching and training doctors in training and other healthcare professionals, therefore he/she is a trainer. However, most board-certified consultant physicians don't has adequate knowledge and experience in training. Therefore, enrolling board-certified consultant physician in a (TOT) training course is necessary to develop him/her into professional trainer. A board-certified consultant physician who has a TOT course certificate, and has conducted a five training courses successfully over a period of one or two years is generally considered a professional trainer as he or she has already gained adequate experience in training. A board-certified physician who has a TOT certificate, and has conducted many training courses successfully over a period of ten years or more and proved his professional and scientific experiences by acquiring the title of advisor or professor is generally considered an expert professional trainer

\section{References}

1. Al Mosawi AJ (2016) Medical and Healthcare leadership: A training course $1^{\text {st }}$ edn, Saarbrücken. LAP Lambert Academic Publishing, Europe.

2. Al Mosawi AJ (2017) Leadership in Medicine and Healthcare: An accredited training course $1^{\text {st }}$ edn, Saarbrücken. LAP Lambert Academic Publishing, Europe.

3. Al Mosawi AJ (2014) Principles of training and development for physicians $1^{\text {st }}$ edn, Saarbrücken. LAP Lambert Academic Publishing, Europe.

4. Al Mosawi AJ (2017) An accredited training of the trainers (TOT) training course $1^{\text {st }}$ edn, Saarbrücken. LAP Lambert Academic Publishing, Europe.

5. Fullarton GM, Darling K, Williams J, MacMillan R, Bell G (1994) Evaluation of the cost of laparoscopic and open cholecystectomy. Br J Surg 81(1): 124-126.

6. Garavan TN, Costine P, Heraty N (1995) Training and Development: Concepts, Attitudes, and Issues. Training and Development in Ireland. Cengage Learning EMEA.

7. Patrick J (2000) Montana and Bruce H. Charnov. Training and Development Management. Barron's Educational Series pp: 225.

8. Harrison R (2005) Learning and Development. CIPD Publishing. pp:5.

9. Al Mosawi AJ (2012) Medical leadership. LAP LAMBERT Academic Publishing GmbH\& Co. KG, Saarbrücken. Germany.

10. Al Mosawi AJ (2007) Continuing Medical education: Principles, concepts, and standards. The New Iraqi Journal of Medicine 3 (2): 32-35.

11. Al Mosawi AJ (2005) Our Experience with continuing medical education (CME) programme. The CME center, University Hospital in ALKadhimiyia. The N Iraqi J Med 1(3): 8-9.

12. Phillips J (1996) How much is the training worth? Training and Development 50(4): 20-24.

13. Morrison GR, Ross SM, Kemp JE, Kalman H (2010) Designing effective instruction. John Wiley \& Sons.

14. Kemp JE, Cochern GW (1994) Planning for effective technical training: A guide for instructors and trainers. Educational Technology.

15. Reiser RA (2001) A history of instructional design and technology: Part II: A history of instructional design. Educational technology research and development 49(2): 57-67.

16. Kirkpatrick DL (1994) Kirkpatrick JD. Evaluating Training Programs, Berrett-Koehler Publishers.

17. Kirkpatrick DL, Kirkpatrick JD (2005) Transferring Learning to Behavior. Berrett-Koehler Publishers.

18. Kirkpatrick DL, Kirkpatrick JD (2007) Implementing the Four Levels, Berrett- Koehler Publishers.

19. Cheng YC, Yeh HT (2009) From concepts of motivation to its application in instructional design: Reconsidering motivation from an instructional 
design perspective. British Journal of Educational Technology 40(4) 597-605.

20. Kemp J (1985) The Instructional Design Process. New York, NY: Harper Row.

21. Fleming N, Baum D (2006) Learning styles again: VARKing up the right tree. Educational Developments 7(4): p.47.

22. Smith LD, Woodward WR (1996) BF Skinner and behaviorism in American culture. Bethlehem PA: Lehigh University Press, USA.

23. Duffy TM, Jonassen DH (1992) Constructivism: New implications for instructional technology. In T. Duffy and D Jonassen (Eds.), Constructivism and the technology of instruction pp. 1-16.

24. Duffy TM, Cunningham DJ (1996) Constructivism: Implications for the design and delivery of instruction. In D Jonassen (Eds.), Handbook of Research for Educational Communications and Technology, New York: Simon \& Schuster Macmillan pp. 170-198.

25. Susan Pass (2004) Parallel Paths to Constructivism: Jean Piaget and Lev Vygotsky, Information Age Publishing p.74.

26. Bloom BS (1956) Taxonomy of Educational Objectives. Allyn and Bacon, Boston, MA.

27. Bloom BS, Engelhart MD, Furst EJ, Hill WH, Krathwohl DR (1956) Taxonomy of educational objectives: The classification of educational goals. Handbook I: Cognitive domain. New York: David McKay Company.
28. Krathwohl DR, Bloom BS, Masia BB(1964) Taxonomy of educational objectives: The classification of educational goals. Handbook II: the affective domain. New York: David McKay Company.

29. Morshead RW (1965) On Taxonomy of educational objectives Handbook II: Affective domain. Studies in Philosophy and Education 4 (1): 164170.

30. Anderson, Lorin W, Krathwohl, David R (2001) A taxonomy for learning, teaching, and assessing: A revision of Bloom's taxonomy of educational objectives. Allyn and Bacon.

31. Krathwohl DR (2002) A revision of Bloom's taxonomy: An overview. Theory into Practice. Routledge 41 (4): 212218.

32. BJ Jansen, D Booth, B Smith (2009) Using the taxonomy of cognitive learning to model online searching. Information Processing \& Management 45(6): 643-663.

33. Skinner BF (1958) Verbal Behavior. Acton, MA: Copley Publishing Group.

34. Skinner BF (1966) Contingencies of Reinforcement. New York; AppletonCentury-Crofts.

35. Martin Jay (2002) The Education of John Dewey. Columbia University Press, New York pp. 406.

36. Knowles MS (1962) A History of the Adult Education Movement in the USA, New York.

37. Knowles M (1984) Andragogy in Action. San Francisco: Jossey-Bass.

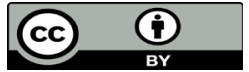

This work is licensed under Creative Commons Attribution 4.0 License

To Submit Your Article Click Here:

Submit Article

DOI: $10.32474 /$ RRHOAJ.2019.04.000187

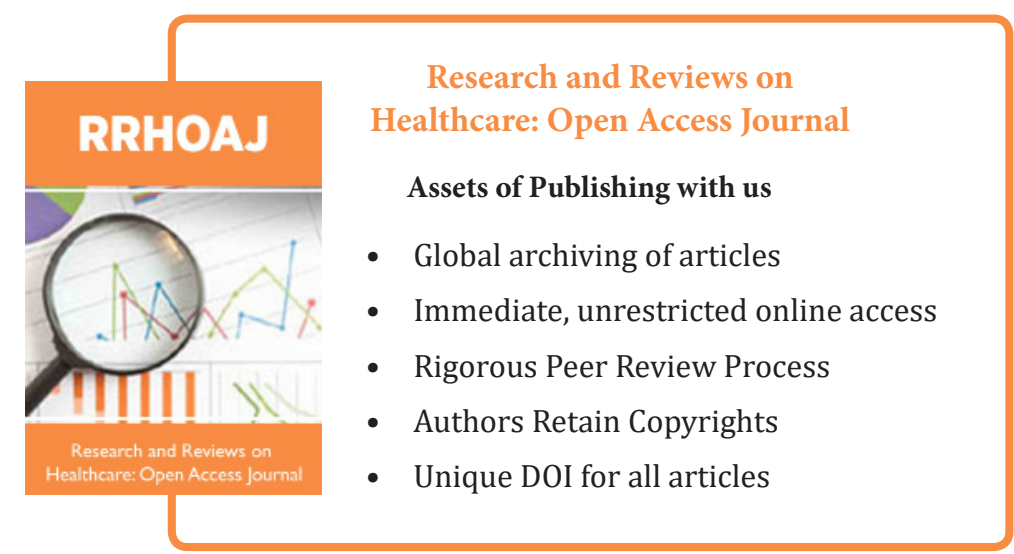

